Article

\title{
Technical Feasibility and Comprehensive Sustainability Assessment of Sweet Sorghum for Bioethanol Production in China
}

\author{
Xiaolin Yang ${ }^{1,2,+}$, Meng $\mathrm{Li}^{1,2,+}$, Huihui Liu ${ }^{1,2}$, Lantian Ren ${ }^{1,2}$ and Guanghui Xie ${ }^{1,2, *}$ \\ 1 College of Agronomy and Biotechnology, China Agricultural University, No. 2, Yuanmingyuan West Road, \\ Haidian District, Beijing 100193, China; yangxiaolin429@163.com (X.Y.); littleboyzhao@163.com (M.L.); \\ attaboylhh@126.com (H.L.); sky1981007@163.com (L.R.) \\ 2 National Energy R\&D Center for Non-Food Biomass, China Agricultural University, Beijing 100193, China \\ * Correspondence: xiegh@cau.edu.cn; Tel.: +86-010-6273-4888; Fax: +86-010-6273-4851 \\ $\dagger$ The authors contributed equally to this work.
}

Received: 8 January 2018; Accepted: 28 February 2018; Published: 7 March 2018

\begin{abstract}
Under dual pressures of energy and environmental security, sweet sorghum is becoming one of the most promising feedstocks for biofuel production. In the present study, the technical feasibility of sweet sorghum production was assessed in eight agricultural regions in China using the Sweet Sorghum Production Technique Maturity Model. Three top typical agricultural zones were then selected for further sustainability assessment of sweet sorghum production: Northeast China (NEC), Huang-Huai-Hai Basin (HHHB) and Ganxin Region (GX). Assessment results demonstrated that NEC exhibited the best sustainable production of sweet sorghum, with a degree of technical maturity value of 0.8066 , followed by HHHB and GX, with corresponding values of 0.7531 and 0.6594 , respectively. Prospective economic profitability analysis indicated that bioethanol production from sweet sorghum was not feasible using current technologies in China. More efforts are needed to dramatically improve feedstock mechanization logistics while developing new bioethanol productive technology to reduce the total cost. This study provides insight and information to guide further technological development toward profitable industrialization and large-scale sweet sorghum bioethanol production.
\end{abstract}

Keywords: sweet sorghum; technical feasibility; sustainability assessment; bioethanol production potential; economic profitability

\section{Introduction}

The increasing world population and the rapid development of a global economy created a huge strain on energy resources and the environment [1]. Recently, China has become the country that consumes the most energy worldwide, surpassing even the USA [2]. Meanwhile, high energy consumption has placed great pressure on the environment in diverse ways, including increases in greenhouse gas emissions (GHGs). Due to these concerns, the search for alternative sources of energy has become the highest priority for China's government [3]. Biofuels are regarded as the best alternative fuel source, due to their renewability and less environmental pollution $[4,5]$ and bioethanol is the main biofuel currently in use [6]. However, China faces high demand for food in addition to high energy demands. Therefore, any bioenergy program must ultimately maintain a balance between food and fuel. Maintaining this balance has been a difficult task, as ethanol production using corn grain has previously been reported to be ecologically unsustainable [7] and conflicting with food security priorities [8,9]. Meanwhile, sweet sorghum [Sorghum bicolor (L.) Moench] has become a promising non-food energy crop [10], due to its high biomass, saline-alkaline resistance [11], drought-tolerance [12,13] and the large amounts of fermentable carbohydrates in its juice-rich stalks [14,15]. In addition, sorghum cultivation has been reported to be sustainable with the use of crop rotation $[10,16]$. 
Much progress has been made through extensive research conducted on sweet sorghum worldwide. Therefore, abundant knowledge has been obtained with regard to breeding, genetics and variety selection [16,17], crop physiology [18,19] and production techniques [19-21]. Advances in production techniques have been made in areas including irrigation [11,22], fertilizer use [22,23], nutrient uptake [24], plant density [20,25,26], harvest date [14,15,25] and lodging control. In the areas of Tianjin, Anhui, Hainan, Heilongjiang, Xinjiang and Inner Mongolia, a previous study [26] demonstrated that the effect of environmental impact factor (E) on sweet sorghum growth was greater than either $\mathrm{G}$ (genotype) or the $\mathrm{G} \times \mathrm{E}$ (interaction effect) based on the Radial Basis Function (RBF) network model with stepwise regression. It has also been reported [27] that sweet sorghum can grow in extreme environmental conditions, such as in regions with an annual effective accumulated temperature greater than 2500 degree days (above $10^{\circ} \mathrm{C}$ ), soil pH between $5.0-8.5$ and soil gravel content $<85 \%$. Other research [28] has clarified that soil $\mathrm{pH}$, total nitrogen and available potassium exert great influence on relative yield and quality of sweet sorghum, subsequently leading to additional studies focusing on yield and production potential of sweet sorghum for bioethanol production $[3,11,14,29,30]$. One study reported that bioethanol from sweet sorghum could reach 1250-5625 L/ha, equal to that obtained from $9000-11,250 \mathrm{~kg}$ of grain crop [29]. Meanwhile, the economic benefit of growing sweet sorghum was estimated to approach 1214 USD/ha, a much higher benefit than for soybean or corn, crops that are already profitable for farmers. Another study [31] demonstrated that ethanol yield produced from sweet sorghum $(6106 \mathrm{~L} / \mathrm{ha})$ was much higher than that of sugarcane $(4680 \mathrm{~L} / \mathrm{ha})$. Another study [14] reported general grain and stalk yields of 2.3-3.0 t/ ha and 67.5-82.5 t/ha, respectively, with $12-18 \%$ sugar content in juice; fuel ethanol production could reach as high as $5250 \mathrm{~L} /$ ha. However, systematic reports on the yield and feasibility of various sweet sorghum cultivation practices for bioethanol production spanning all agricultural zones of China have rarely been published.

Recently, more efforts have been expended to study overall energy output [32,33], ecological sustainability [34] and economic benefit [31,35-38] of sweet sorghum as a bioethanol feedstock. One study reported that sweet sorghum had a lower energy input requirement and a higher energy productivity than cotton and maize on the coastal saline-alkaline lands in Shandong Province and Inner Mongolia [33]. Meanwhile, another study demonstrated that development of sweet sorghum bioethanol relieved energy constraints, was conducive to agricultural production and industrial progress, while being favorable to the environment [31]. Moreover, the net economic output of sweet sorghum cultivation has also been reported to be significantly higher than for other staple crops in Xinjiang and Shandong Province [31,35]. Other research [32] has reported good sustainability, higher resource utilization, lower GHGs and lower need for pesticide application in sweet sorghum production in China, oil palm in Southeast Asia and sugarcane in Brazil; this compared favorably with poor sustainability for corn grown in the U.S. and wheat grown in northwestern Europe. Economically, the net revenue of the commercial sweet sorghum bioethanol industry reached $219 \times 10^{4}$ USD/ha, with a return on investment of $15.11 \%$ in a seven-year investment recovery period [36]. Meanwhile, another group [31] reported that the cost of bioethanol production using sweet sorghum is much lower, by around $46.5-57.5 \%$, than costs using sugar beet feedstock; this agrees with another study [38] reporting consistently lower production costs of sweet sorghum as ethanol feedstock than costs for competing crops such as corn, cotton and soybean, as demonstrated by economic feasibility analysis in the southeastern U.S. After economic analysis [35], sweet sorghum as an energy crop for ethanol production showed a better return to scale on investment than cotton and sunflower in North China. Indeed, the large-scale cultivation and processing of sweet sorghum was reported to increase the farms' economic incomes, reduce the cost of production and conversion and promote the development of husbandry, sugar manufacturing, bioenergy and papermaking [37]. However, a comprehensive sustainability assessment of sweet sorghum including cultivation, energy and economic input-output ratio, environmental effects, etc., has not yet been done for the major agricultural regions across China. 
Because sweet sorghum holds great promise as a highly advantageous renewable bioenergy crop, more research is needed in order to support large-scale utilization of this crop for bioenergy production. In the handful of published studies, previous energy efficiency and economic benefit analyses of sweet sorghum conversion to bioethanol have mainly focused on a specific region or a single aspect of the process. Consequently, both a comprehensive sustainability assessment of cultivation practices and a thorough economic feasibility evaluation of bioethanol production for sweet sorghum in the various farming zones across China are needed. Therefore, the objectives of this study are to (1) identify the technical feasibility of sweet sorghum production in major farming zones across China; (2) analyze the sustainability of sweet sorghum production based on a literature review and investigate promising topics comprehensively; (3) reveal the prospective economic profitability of sweet sorghum bioethanol production as biomass feedstock using the current bioethanol conversion technology in China.

\section{Materials and Methods}

\subsection{Agricultural Zones}

According to the book of "Agricultural Resources and Regional Planning in China" [39], the nation was divided into geographical farming zones comprised of county administrative districts by considering social, economic and basic agricultural production practices, as well as developmental direction and main production problems and solutions (Figure 1). These zones are designated as Northeast China (NEC), Huang-Huai-Hai Basin (HHHB), Ganxin Region (GX), Inner-Mongolia and zone along the Great Wall (IZG), Loess Plateau (LP), Southwest China (SWC), Middle-lower area of Yangtze Basin (MLYB), South China (SC) and Qinghai plus Tibet plateau (QT). Due to the cold climate in QT, sweet sorghum is rarely planted there [40]. QT was excluded, leaving eight zones to analyze.

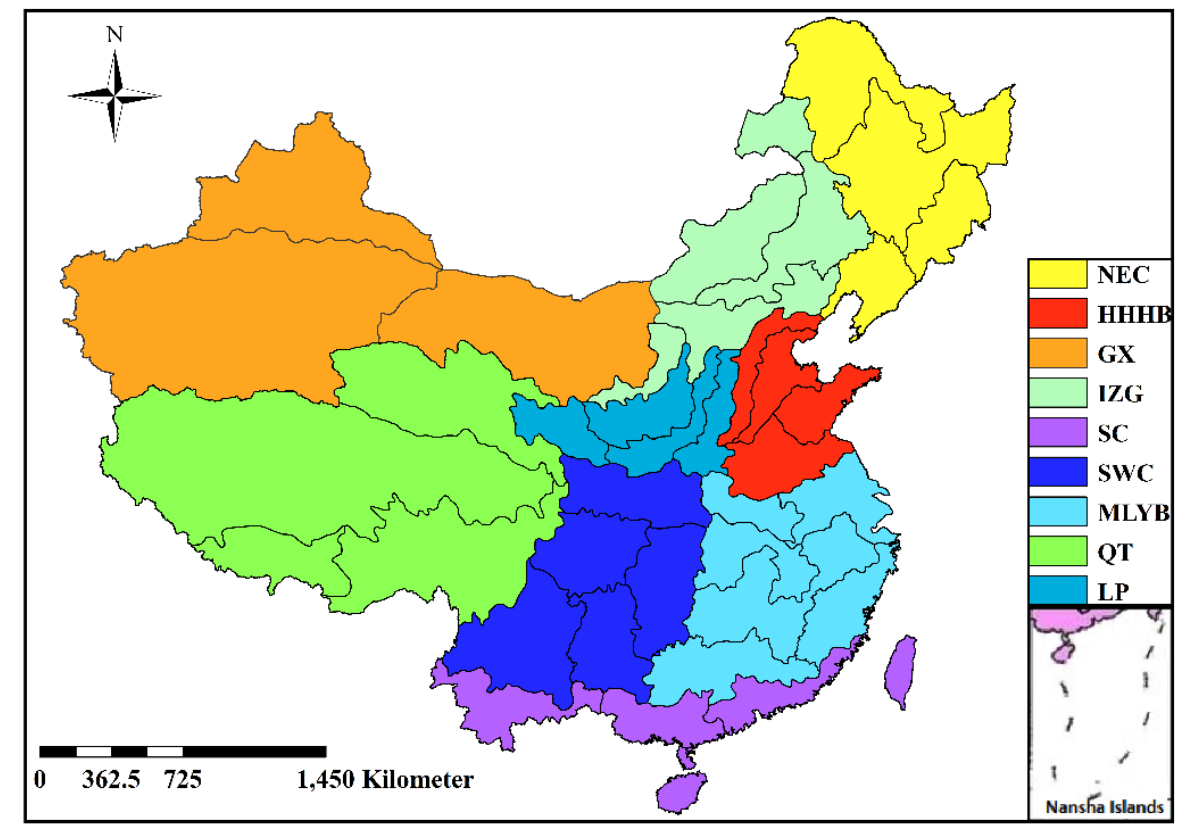

Figure 1. Comprehensive agricultural zoning map in China.

\subsection{Evaluation of Technical Feasibility of Sweet Sorghum Production}

In this study, a research literature review of sweet sorghum grown in the major farming regions was performed and the bulk of the work was divided into four categories: breeding techniques (variety selection, introduction and breeding, genetics, etc.), cultivation management (cultivation technology such as plant density, sowing date, fertilization, etc.), storage techniques (storage experiments in each region) and stress physiology (drought, salinity and alkalinity, heavy metals, etc.). All references 
were obtained from published Chinese and English research literature using "sweet sorghum" as keyword and limiting the search results to the most recent 15 years for searching of databases including "Web of Science," "China Knowledge Resource Integrated (CNKI)" and the "WanFang Database." The aforementioned indicators were used to compare and analyze the Degree of Technical Maturity (DTM) of sweet sorghum production in various regions. Each phase of sweet sorghum production is also affected by local economic development and climatic conditions.

A rapid analysis method designated as the "Sweet Sorghum Production Technique Maturity Model (SPTM)" in this study was used to evaluate the degree of technical maturity (DTM) of sweet sorghum production practices in various regions, as assessed using the aforementioned four indicators (breeding, cultivation, storage and stress-resistance). The calculation codes of SPTM are detailed in Supplementary Materials File 1. The proposed technique is based on the theory of Grey Relational Grade Analysis (GRGA), which is one of the essential components of grey systems theory formulated by Deng [41]. The weights of the studied indicators were defined according to the evaluation criteria and the DTM assessment determined in this study. Breeding technique, cultivation management and storage technique are the key indicators of sweet sorghum production. The weights of these three indicators were each assigned a value of 0.3 in this study. The weight of the indicator of stress physiology was assigned to be 0.1 , due to sweet sorghum's strong resistance to environmental stresses. Assuming that the DTM has a positive correlation with the numbers of discovered local research publications, the maximum value of each indicator across eight regions was regarded as the indicator's theoretical optimum value. This method uses matrix calculation to quantify the data in different levels and transforms multiple responses into a single grey relational grade, so that the DTM could be comprehensively and fairly evaluated with a single dimensionless value. The DTM was assigned to one of four grades reflecting the technical level of sweet sorghum production, including very immature, immature, generally mature and mature, where the corresponding DTM ranged between [0, 0.25], $[0.25,0.50],[0.50,0.75]$ and $[0.75,1.00]$, respectively.

\subsection{Comprehensive Sustainability Assessment of Sweet Sorghum Production}

Based on the results of the technical feasibility evaluation, three typical agricultural production regions, including NEC, HHHB and GX, were selected to represent the various soil and climate types and were subjected to comprehensive sustainability assessment of sweet sorghum production. In each of these three zones, typical study sites in the zone's main planting area of sweet sorghum were selected according to the natural environmental conditions and planting characteristics [37]. The main conditions including position, climate and soil characteristics of the selected study sites are detailed in Table 1.

The sustainability assessment boundary began with soil preparation and included film mulching, basal fertilizer dressing, sowing, thinning out of seedlings, weeding, tiller removal, topdressing, pesticide application, irrigation, spikelet removal, harvesting, bundling, transportation, threshing to storage and marketing (Figure 2).

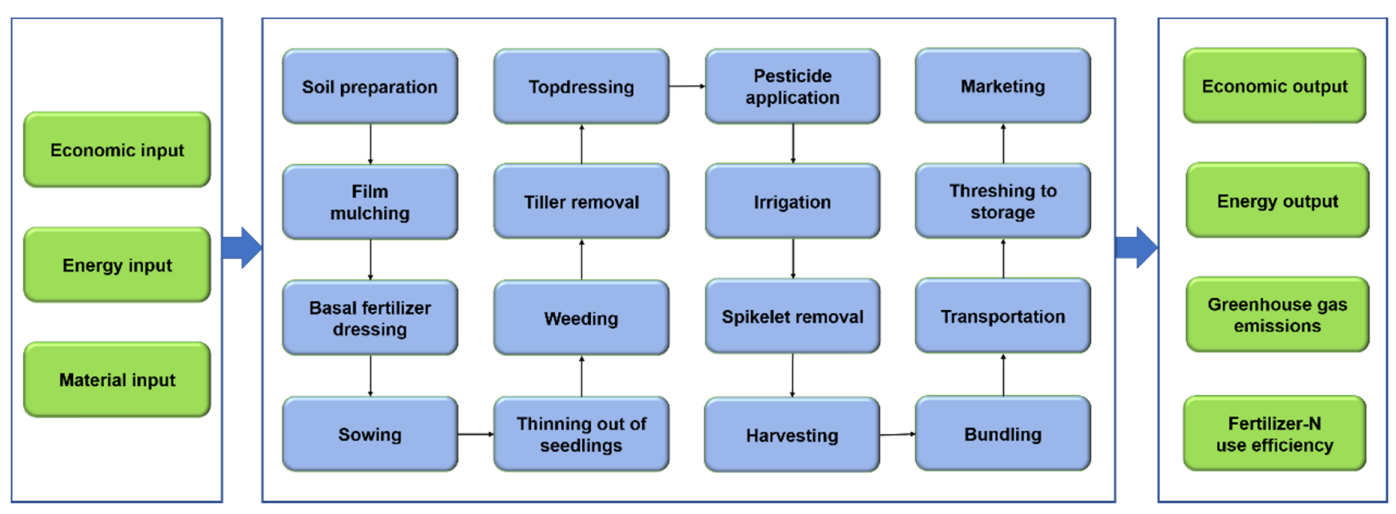

Figure 2. Sustainability assessment boundary in typical agricultural production regions. 
Table 1. Main characteristics of the selected typical study sites in this study.

\begin{tabular}{|c|c|c|c|c|c|c|c|c|}
\hline \multirow{2}{*}{ Item } & \multirow{2}{*}{ Unit } & \multicolumn{2}{|c|}{ Northeast China (NEC) ${ }^{\#}$} & \multicolumn{2}{|c|}{ Huang-Huai-Hai Basin (HHHB) ${ }^{\#}$} & \multicolumn{3}{|c|}{ Ganxin Region (GX) ${ }^{\#}$} \\
\hline & & Huachuan* & Morin Dawa * & Wudi * & Wendeng * & Turpan * & Wuyuan * & Gulang * \\
\hline \multicolumn{9}{|l|}{ Position: } \\
\hline East-longitude & & $130^{\circ} 16^{\prime}-131^{\circ} 34^{\prime}$ & $123^{\circ} 33^{\prime}-125^{\circ} 16^{\prime}$ & $117^{\circ} 31^{\prime}-118^{\circ} 04^{\prime}$ & $121^{\circ} 57^{\prime}-122^{\circ} 17^{\prime}$ & $87^{\circ} 14^{\prime}-91^{\circ} 54^{\prime}$ & $107^{\circ} 35^{\prime}-108^{\circ} 37^{\prime}$ & $102^{\circ} 38^{\prime}-103^{\circ} 54^{\prime}$ \\
\hline Altitude & $\mathrm{m}$ & $60-70$ & $173-638.3$ & 50 & 257 & $-154-4000$ & 1019-1035 & $1550-3469$ \\
\hline \multicolumn{9}{|l|}{ Climate: } \\
\hline Precipitation & $\mathrm{mm}$ & 476.4 & $400-500$ & 598.6 & 768.4 & $3.9-25.5$ & 177 & 250 \\
\hline Annual average temperature & ${ }^{\circ} \mathrm{C}$ & 2.5 & 3.2 & 12.1 & 11.4 & 13.9 & 6.1 & 5.2 \\
\hline Annual highest temperature & ${ }^{\circ} \mathrm{C}$ & 36.8 & 39.5 & 26 & 24.6 & 32.7 & 22.7 & 37.2 \\
\hline Annual lowest temperature & ${ }^{\circ} \mathrm{C}$ & -39.7 & -45 & -4 & -1.4 & -9.5 & -13.2 & -26.4 \\
\hline accumulated temperature $\geq 10^{\circ} \mathrm{C}$ & ${ }^{\circ} \mathrm{C}$ & $2500-2700$ & $1815-2413$ & 4339 & 4000 & 5455 & 2896 & 2686 \\
\hline Frost-free season & day & 133 & $100-134$ & 206 & 221 & $250-300$ & $117-136$ & 150 \\
\hline Annual sunshine hours & $\mathrm{h}$ & $2500-2600$ & $2500-2800$ & 2724.5 & 2512 & 3056 & 3231 & 2852 \\
\hline Annual average evaporation & $\mathrm{mm}$ & 1275 & $1050-1450$ & 1238 & $1500-1700$ & $2879-3822$ & 2039 & 2807 \\
\hline \multicolumn{9}{|l|}{ Soil: } \\
\hline $\mathrm{pH}$ value & & 6.62 & 6.8 & $7.0-7.5$ & 6.8 & $8.6-9.1$ & 8.4 & 8.0 \\
\hline Organic matter & $\%$ & 4.46 & $4.15-10.0$ & 1.31 & 1.2 & 4.04 & 1.17 & 1.54 \\
\hline Total nitrogen & $\%$ & 0.23 & $0.28-0.67$ & 0.47 & 0.71 & 0.22 & 0.54 & 0.096 \\
\hline Available N & $\mathrm{mg} / \mathrm{kg}$ & 163.7 & N/A & 58.53 & $\mathrm{~N} / \mathrm{A}$ & 63.56 & 52.37 & 75.5 \\
\hline Available K & $\mathrm{mg} / \mathrm{kg}$ & 158.3 & $150-200$ & 158.45 & 51 & 165.67 & 157.9 & $\mathrm{~N} / \mathrm{A}$ \\
\hline Reference & & {$[9,42]$} & [43-45] & [46-48] & [49-51] & {$[52,53]$} & [54-56] & [57-59] \\
\hline
\end{tabular}

${ }^{\#}$ denotes the selected three zones after the technical feasibility evaluation. ${ }^{*}$ denotes the selected typical study sites in each zone. 
In order to make a comprehensive sustainability assessment, the National Energy R\&D Center for Non-food Biomass (NECB) obtained a total of 481 questionnaires based on face-to-face interviews with farmers in NEC (Morin Dawa Banner), HHHB (Wudi County and Wendeng County) and GX (Wuyuan County) during a four-year sustainability analysis of sweet sorghum production supported by National Energy Administration of China [33,35].

Multiple evaluation factors of sustainability assessment included energy efficiency, environmental effects, economic benefit, etc., as described below.

\section{(1) Energy output}

In this study, the energy efficiency evaluation was based on two indices. One was the energy input-output ratio of sweet sorghum production, which was defined as the energy contained in both the stalk, as the main product and the grain, as the by-product, divided by the energy consumed in the cultivation and transportation of the sweet sorghum. Considering the scarcity of land resources in China, the available land area is of utmost importance for calculating sweet sorghum energy production. The other important indicator is net energy output per unit of land area, which was defined as the energy contained in the stalk and the grain minus the energy consumed in the cultivation and transportation of the sweet sorghum.

\section{(2) Greenhouse gas emissions}

Reducing the greenhouse gas emissions (GHGs) was the original intent behind development of biofuels [48]. Notably, the sweet sorghum cultivation phase is the main source of greenhouse gas emissions in bioethanol life cycle, including the use of diesel fuel and electricity consumption to conduct irrigation, as well as the production and application of nitrogen fertilizer [22]. The GHGs, as the second indicator, consist of the emissions generated during the growth and transportation of sorghum straw per kilogram. The economic value approach was applied to allocate the percentages of the emissions to the stalks as main products and to grains as by-products in the sweet sorghum cultivation phase.

\section{(3) Economic benefit}

The economic profitability of the farmers directly influences whether they plant bioenergy crops instead of conventional food crops. Therefore, assessment of profitability is crucial to the development of bioenergy crops for production of liquid biofuels [1]. Farmers' incomes correlate directly to planting costs, biomass yield and market price of sweet sorghum [35]. In this study, the economic input-output ratio, as another indicator, was defined as the economic output of both the stalks as main products and grain as by-products divided by the cost input of sweet sorghum's production and transportation. The net economic output is the difference between the economic output and input.

\section{(4) Nitrogen fertilizer}

Fertilizer-leaching pollution, especially of nitrogen and phosphorus fertilizers applied during agricultural production, is both detrimental to ecosystems and to drinking water quality [4]. This study focuses on the $\mathrm{N}$ fertilizer, which had the strongest influence on sustainable development. $\mathrm{N}$ fertilizer generation consumes much energy and causes a vast quantity of GHGs that increase in direct proportion with $\mathrm{N}$ application. The $\mathrm{N}$ fertilizer use efficiency [60], as an indicator, was defined as the net energy produced per $\mathrm{kg}$ of $\mathrm{N}$ fertilizer application. Cultivation practices of sweet sorghum are relatively simple in China, with little application of either pesticides or irrigation [35], thus, these factors were ignored in this study.

Assuming that the weights of the effects of the above indicators on the sustainability of sweet sorghum production are equal, we took the maximum value of each indicator (except GHGs) as 100 for the degree of sustainability, with the others calculated in proportion. As for the greenhouse 
gas emissions, the minimum is the basal value, defined as 100 and the value of other emissions is calculated using the formula:

$$
\mathrm{y}=(\text { other emission }- \text { minimum emission }) / \text { minimum emission } \times 100-100
$$

\subsection{Economic Profitability Assessment of Sweet Sorghum Bioethanol Production}

\subsubsection{Theoretical Bioethanol Production Potential for Selected Sites}

In view of the lack of commercial scale sweet sorghum cultivation in China, a demonstration process was developed and evaluated based on Advanced Solid-State Fermentation (ASSF) technology with minor modifications [61,62]. In this scheme, bioethanol was produced by conversion of starch extracted from grain and from sugar in stem juice (Figure 3). The conversion factors of fuel ethanol from grain and juice were $430.38 \mathrm{~L} / \mathrm{t}$ and $79.11 \mathrm{~L} / \mathrm{t}$, respectively. Using this system, the theoretical production potential of ASSF could be calculated as follows.

Ethanol yield from grain $(\mathrm{L} / \mathrm{ha})=430.38$ (conversion factor of fuel ethanol from grain, $\mathrm{L} / \mathrm{t}) \times$ grain yield $(\mathrm{t} / \mathrm{ha})$

Ethanol yield from juice $(\mathrm{L} / \mathrm{ha})=79.11$ (conversion factor of fuel ethanol from

$$
\text { juice, } \mathrm{L} / \mathrm{t}) \times \text { stem yield }(\mathrm{t} / \mathrm{ha})
$$

Total ethanol yield from sweet sorghum $(\mathrm{L} / \mathrm{ha})=$ Ethanol yield from grain $(\mathrm{L} / \mathrm{ha})+$ Ethanol yield from juice $(\mathrm{L} / \mathrm{ha})$

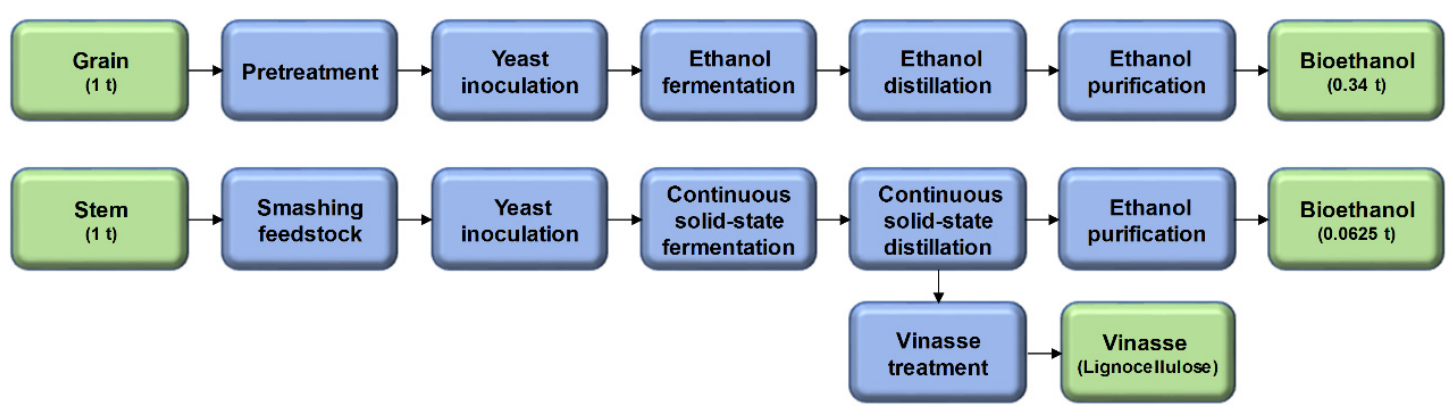

Figure 3. Schematic representation of Advanced Solid-State Fermentation (ASSF).

\subsubsection{Prospective Economic Profitability of ASSF for Selected Sites}

In 2002, the Chinese central government issued the "Announcement on Issue of Detailed Rules of Implementation for the Extension of the Pilot Program of Ethanol Alcohol Gasoline for Vehicles" ([2004] 230) to officially set the price of fuel ethanol, which is calculated as 0.911 times the market price of 93 octane gasoline. For a reliable calculation of prospective economic profitability, the price of fuel ethanol was set to 0.97 USD $/ \mathrm{kg}$ based on the average value from 2011 to 2015 [30]. According to our previous study, the price of sweet sorghum logistics including storage and transportation is $52.64 \mathrm{USD} / \mathrm{t}$ for the current biomass feedstock supply in North China [1]. The cost of grain ethanol production (632.23 USD/t) included the purchase cost of grain feedstock from farmers and the cost of the ethanol conversion process [62]. Similarly, the cost of stem juice ethanol production (615.4 USD/t) included the purchase cost of stem feedstock from farmers and the cost of the ethanol conversion process [61]. The prospective economic profitability of ASSF would then be calculated as follows:

Economic inputs of sweet sorghum logistics (USD/ha) $=52.64$ (the price of sweet sorghum logistics, USD/t) $\times$ biomass yield (the sum of grain and stem yield, $t /$ ha) 
Economic inputs of fuel ethanol production (USD/ha) $=632.23$ (the cost of fuel ethanol production from grain, $\mathrm{USD} / \mathrm{t}) \times$ ethanol yield from grain $(\mathrm{L} / \mathrm{ha})$

$\times 0.79$ (specific gravity of ethanol, $\mathrm{kg} / \mathrm{L}$ ) $/ 1000+615.4$ (the cost of fuel ethanol production from stem, USD $/ \mathrm{t}) \times$ ethanol yield from stem $(\mathrm{L} / \mathrm{ha})$

$\times 0.79$ (specific gravity of ethanol, $\mathrm{kg} / \mathrm{L}$ ) $/ 1000$

Economic outputs of fuel ethanol production $(\mathrm{USD} / \mathrm{ha})=0.97(\mathrm{USD} / \mathrm{kg}) \times$ total ethanol yield from sweet sorghum $(\mathrm{L} / \mathrm{ha}) \times 0.79$ (specific gravity of ethanol, $\mathrm{kg} / \mathrm{L}) / 1000$

Theoretical net economic output (USD/ha) = outputs of fuel ethanol production (USD/ha)-inputs of sweet sorghum logistics (USD/ha)-inputs of fuel ethanol production (USD/ha)

\subsection{Statistical Analysis}

The sweet Sorghum Production Technique Analysis Model (SPTM) was developed using MATLAB 2014b (The MathWorks Inc., Natick, MA, USA); the procedure code can be found in Supplementary Materials File 1. Means, standard deviations and ANOVA analyses were calculated using IBM SPSS Statistics V.24 (IBM SPSS Inc., Chicago, IL, USA). China Agricultural Resources and Regional Planning Map was made using ArcGIS 10.3 (ESRI Inc., Redlands, CA, USA) and all figures were handled by OriginPro 9.1 (OriginLab Corporation, Northampton, MA, USA).

\section{Results}

\subsection{The Technical Feasibility of Sweet Sorghum Production in China}

As presented in Table 2, normalized publication counts and the weighted DTM index of sweet sorghum were determined using the dedicated SPTM. The DTM of sweet sorghum was highest in the NEC among others (0.8066), followed by the GX (0.7531) and YHH (0.6594) (Table 2), which were all greater than 0.5. Notably, the production DTM level was mature for NEC and GX and generally mature in HHHB. Conversely, DTM values were between 0.3 and 0.4 in the other five areas, which demonstrated that sweet sorghum technology was immature. The ranking of DTM values from high to low in these five regions was MLYB (0.3967) > LP (0.3670) > SC (0.3634) > IZG (0.3564) > SWC (0.3564).

Table 2. Technical level of sweet sorghum production in the four categories and the weighted Degree of Technical Maturity (DTM) in different agricultural zones of China.

\begin{tabular}{ccccccc}
\hline $\begin{array}{c}\text { Agriculture } \\
\text { Region }\end{array}$ & $\begin{array}{c}\text { Breeding } \\
\text { Technique }\end{array}$ & $\begin{array}{c}\text { Cultivation } \\
\text { Technique }\end{array}$ & $\begin{array}{c}\text { Storage } \\
\text { Technique }\end{array}$ & $\begin{array}{c}\text { Stress-Resistance } \\
\text { Physiology }\end{array}$ & DTM & Ranking \\
\hline NEC & 1.0000 & 1.0000 & 0.5385 & 0.4510 & 0.8066 & 1 \\
GX & 0.4851 & 0.8750 & 1.0000 & 0.4510 & 0.7531 & 2 \\
HHHB & 0.4757 & 1.0000 & 0.3889 & 1.0000 & 0.6594 & 3 \\
MLYB & 0.3379 & 0.3784 & 0.4667 & 0.4182 & 0.3967 & 4 \\
LP & 0.3630 & 0.3415 & 0.3684 & 0.4510 & 0.3670 & 5 \\
SC & 0.4336 & 0.3333 & 0.3333 & 0.3333 & 0.3634 & 6 \\
IZG & 0.3333 & 0.3684 & 0.3684 & 0.3538 & 0.3564 & 7 \\
SWC & 0.3333 & 0.3415 & 0.3333 & 0.3333 & 0.3358 & 8 \\
\hline
\end{tabular}

* NEC: Northeast China, IZG: Inner-Mongolia and Zone along the great wall, HHHB: Huang-Huai-Hai Basin, GX: Ganxin Region, LP: Loess Plateau, SWC: Southwest China, MLYB: Middle-lower reaches of Yangtze Basin, SC: South China.

\subsection{Comprehensive Sustainability Assessment of Sweet Sorghum Production}

Due to their highest DTM values, three agricultural production zones, NEC, HHHB and GX, were chosen to conduct a comprehensive sustainability assessment of sweet sorghum production. 
Summary statistics of economic, energy-saving and environmental benefits of sweet sorghum production in NEC, HHHB and GX are detailed in Table 3.

Table 3. Indicators of the sustainability of sweet sorghum production of typical study sites in Northeast China, Huang-Huai-Hai Basin and Ganxin Region.

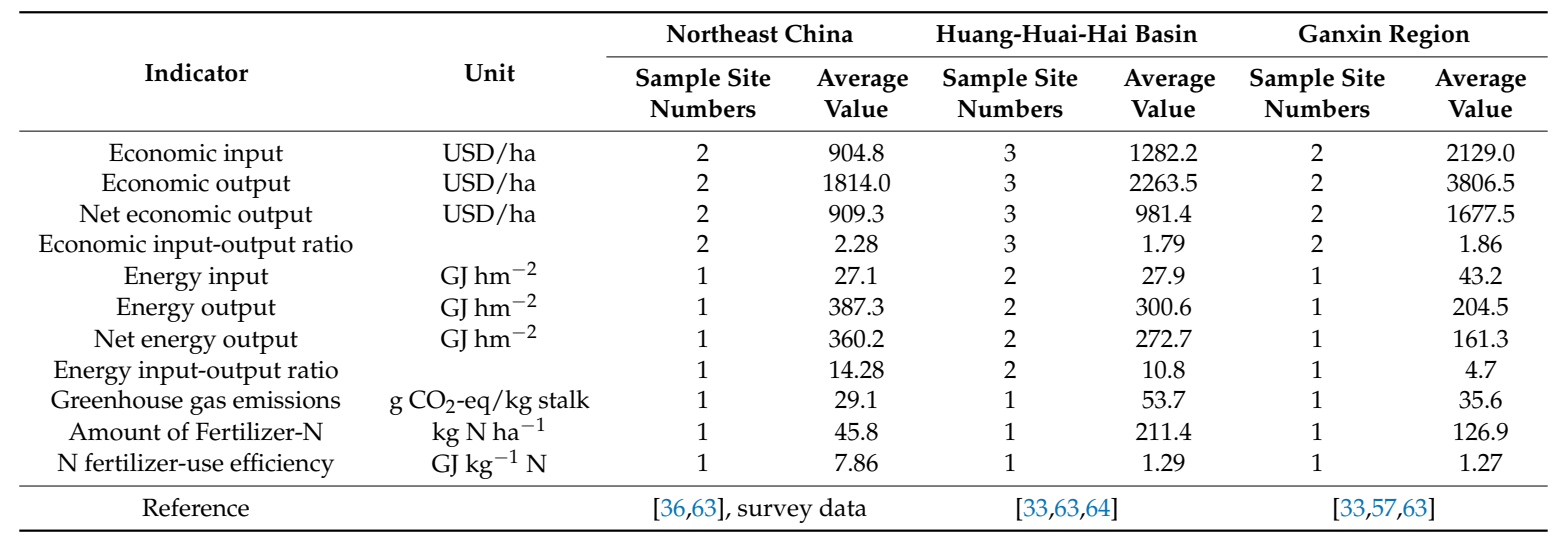

Sample sits of Northeast China comes from the typical study sites of Huachuan, Morin Dawa and East Heilongiiang; sample sits of Huang-Huai-Hai Region comes from Wudi, Wendeng, Cangzhou and North Shandong; sample sites of Ganxin Region comes from Wuyuan, Gulang and Middle Xinjiang. Each of the typical study sites was detailed in Table S1 of Supplementary Materials File 2.

Results showed that the average economic input value of sweet sorghum production was lowest for NEC with the average value of 904.8 USD/ha, followed by HHHB with the average value of 1282.2 USD/ha and the highest in GX with the average value of 2129.0 USD/ha. Economic output value of sweet sorghum production was lowest for GX with the average value of $3806.5 \mathrm{USD} / \mathrm{ha}$, followed by HHHB with the average value of 2263.5 USD/ha and highest for NEC with the average value of 1814.0 USD/ha (Table 3). No significant differences were observed among the two available study sites in NEC and among the three available study sites in HHHB (Table S1). The average net economic output value of sweet sorghum production was lowest for NEC with the average value of $909.3 \mathrm{USD} / \mathrm{ha}$, followed by HHHB with the average value of $981.4 \mathrm{USD} /$ ha and highest for GX with the average value of 1677.5 USD/ha. However, there were large differences among the two available sites in GX where the net economic output of Wuyuan County was negative, around -642.3 USD/ha, while that of Gulang County was positive, approximately +3997.2 USD/ha (Table 3 and Table S1). Finally, the average economic input-output ratios in NEC, HHHB and GX were 2.28, 1.79 and 1.86 , respectively.

The average energy input of sweet sorghum production was highest in Wuyuan County in GX (43.2 GJ/ha) and lower for NEC and HHHB (27.1 GJ/ha and 27.9 GJ/ha, respectively). Energy output was highest in NEC, with 387.3 GJ/ha in Morin Dawa Daur Autonomous Banner, followed by HHHB, with an average of $300.6 \mathrm{GJ} / \mathrm{ha}$ and the lowest in Ganxi with an average of 204.5 GJ/ha in Wuyuan County (Table 3 and Table S1). The ranking of net energy output was similar to that of the energy input-output ratio, with the order of NEC $>$ HHHB $>$ GX.

On a per $\mathrm{kg}$ stalk production basis, GHGs levels were determined after conversion to $\mathrm{CO}_{2}$ equivalent $\left(\mathrm{CO}_{2}\right.$-eq) and were highest in $\mathrm{HHHB}$ with $53.7 \mathrm{~g} \mathrm{CO}_{2}$-eq/ kg stalk in Wudi County, followed by GX, with $35.6 \mathrm{~g} \mathrm{CO}_{2}$-eq/ kg stalk in Wuyuan County and lowest in NEC, with $29.1 \mathrm{~g}$ $\mathrm{CO}_{2}$-eq/kg stalk in Huachuan County (Table 3 and Table S1). Finally, $\mathrm{N}$-fertilizer application exhibited a positive correlation with the GHGs in each research region.

In order to create a visualized comprehensive evaluation of the six indicators of sustainability mentioned above, a spider diagram was adopted (Figure 4). The blue area in each picture represents the sustainability of sweet sorghum production in each research region; the bigger the size of the blue area, the higher sweet sorghum sustainability. It is obvious that the best sustainability of sweet sorghum 
production was observed in NEC (Figure 4a), while relatively poor sustainability was observed in HHHB (Figure $4 b$ ) and GX (Figure 4c).
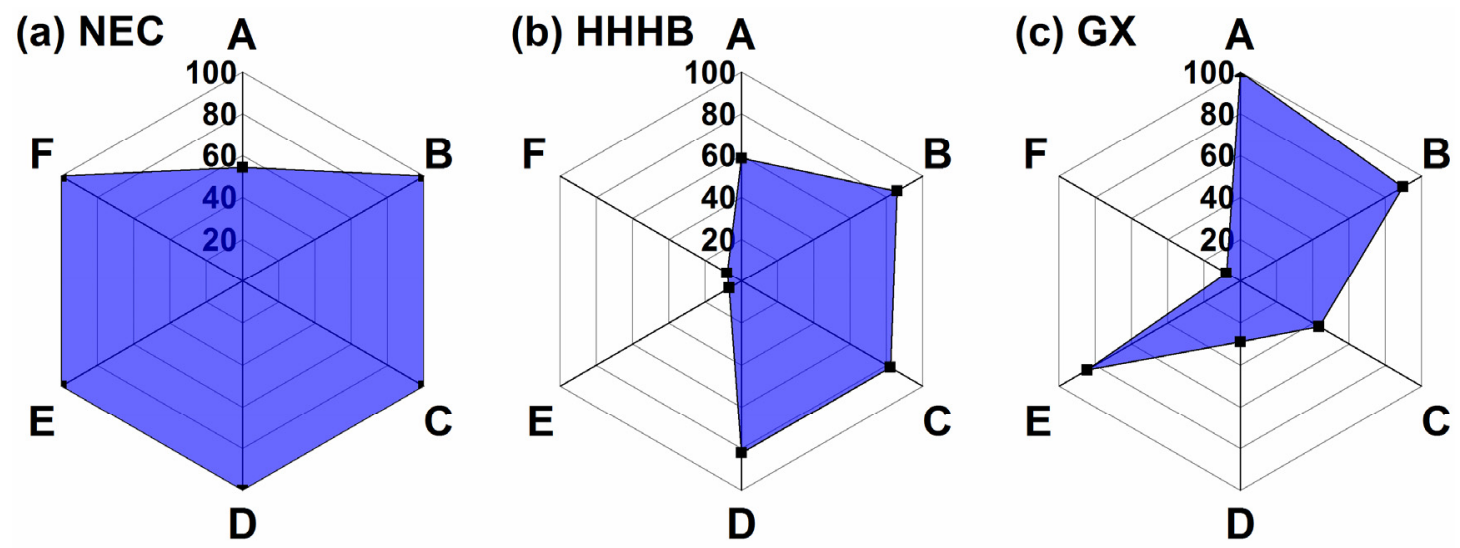

Figure 4. Comparison of the sustainability of sweet sorghum production in (a) Northeast China (NEC), (b) Huang-Huai-Hai Basin (HHHB) and (c) Ganxin Region (GX). A: Net economic output; B: Economic input-output ratio; C: Net energy output; D: Energy input-output ratio; E: Greenhouse gas emissions reduction; F: Nitrogen fertilizer use efficiency.

\subsection{Analysis of Theoretical Bioethanol Productive Potential}

Summary statistics of the grain and stem yields of sweet sorghum in NEC, HHHB and GX are shown in Table 4 [33,35]. Due to late-maturation and absence of a heading stage, no sweet sorghum grain was harvested in NEC. The average grain yield values of sweet sorghum in GX and HHHB were $1.9 \mathrm{t} / \mathrm{ha}$ and $2.1 \mathrm{t} / \mathrm{ha}$, respectively. The average sweet sorghum stem biomass yield was highest in NEC with the average value of $75.0 \mathrm{t} / \mathrm{ha}$, followed by HHHB with the average value of $68.9 \mathrm{t} / \mathrm{ha}$, with the lowest value observed for GX (55.9 t/ha). Overall, NEC obtained the highest biomass yield (75.0 t/ha), followed by HHHB (71.0 t/ha) and GX (57.8 t/ha).

Table 4. Annual average grain and stem yield of sweet sorghum in Northeast China, Huang-Huai-Hai Basin and Ganxin Region.

\begin{tabular}{cccc}
\hline Index & Northeast China & Huang-Huai-Hai Basin & Ganxin Region \\
\hline Grain t/ha & 0 & $2.1 \pm 0.2$ & $1.9 \pm 0.9$ \\
Stem t/ha & $75.0 \pm 15.0$ & $68.9 \pm 3.8$ & $55.9 \pm 13.9$ \\
Biomass t/ha & $75.0 \pm 15.0$ & $71.0 \pm 4.0$ & $57.8 \pm 14.8$ \\
\hline \multicolumn{4}{c}{}
\end{tabular}

To evaluate the theoretical bioethanol production potential of the three selected regions, a demonstration scenario was developed based on Advanced Solid-State Fermentation (ASSF) technology with minor modifications (Figure 3). The results demonstrated that the rank order of the theoretical ethanol yield of stem based on ASSF processing was similar to the rank order of biomass yield: NEC (5933.5 L/ha) > HHHB (5452.5 L/ha) > GX (4422.5 L/ha). Due to higher grain bioethanol yield, the total average bioethanol yield was highest in HHHB with the average value of $6322.4 \mathrm{~L} / \mathrm{ha}$, followed by NEC with the average value of $5933.5 \mathrm{~L} / \mathrm{ha}$, with lowest total bioethanol yield for GX (5228.7 L/ha) (Figure 5). 


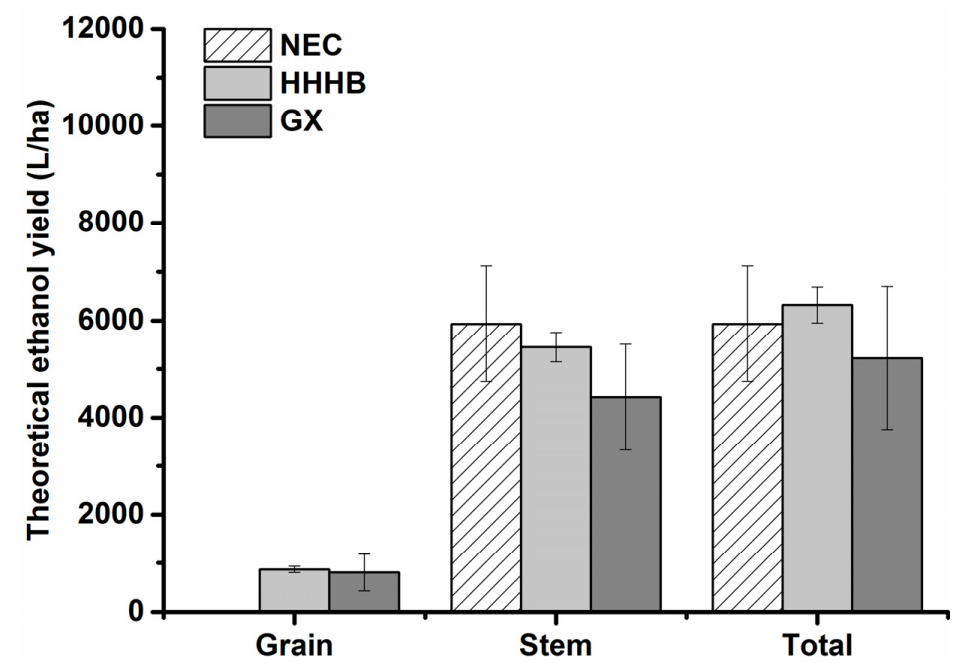

Figure 5. Theoretical bioethanol production potential of sweet sorghum from grain and stem in Northeast China (NEC), Huang-Huai-Hai Basin (HHHB) and Ganxin Region (GX).

\subsection{Prospective Economic Profitability of Sweet Sorghum Bioethanol}

The inputs and outputs of sweet sorghum bioethanol production in NEC, HHHB and GX were compared and analyzed (Figure 6). For the input side, it was obvious that the input of biomass logistics accounted for the largest input factor (54.4 to 57.8\%) followed by stem bioethanol conversion (about 38.4 to $42.2 \%$ ) (Figure 6a). The average input of sweet sorghum bioethanol production was highest for NEC (6832.7 USD/ha), followed by HHHB (6822.8 USD/ha) and lowest for GX (5595.3 USD/ha). The inputs of biomass logistics for the above three corresponding selected sites were 1.37 times, 1.21 times and 1.19 times that of the input of bioethanol conversion, respectively. For the output side, HHHB achieved the highest average output value of bioethanol production (4844.9 USD/ha), followed by NEC (4546.9 USD/ha), with the lowest value for GX (4006.8 USD/ha) (Figure 6b). In short, these results indicate that bioethanol production using sweet sorghum is not feasible or sustainable in any of the selected geographic areas from the standpoint of economic input and output. Based on the current industry technological status for conversion, the ranking of the theoretical net economic output values was GX ( -1588.6 USD/ha) > HHHB (-1977.9 USD/ha) > NEC ( -2285.8 USD/ha). Obviously, bioethanol production using sweet sorghum is still not feasible at the current levels of technology and bioethanol price in China.

(a)

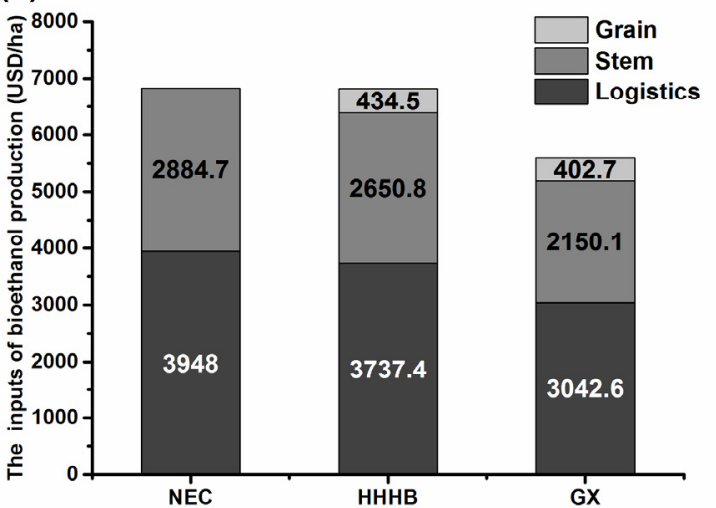

(b)

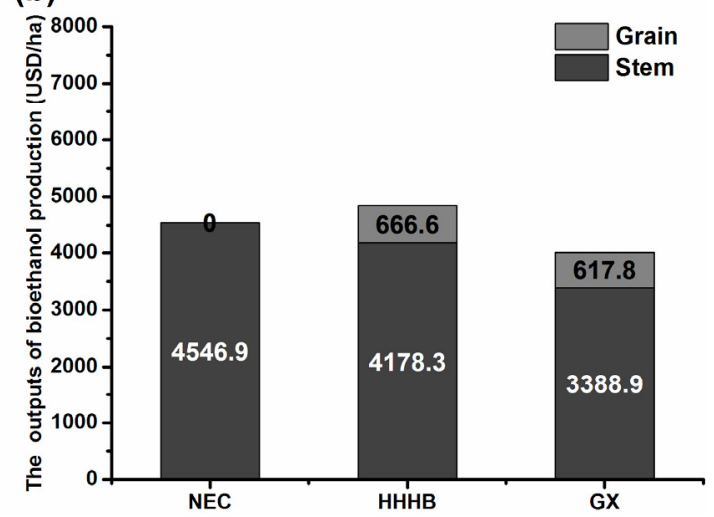

Figure 6. Economic inputs (a) and outputs (b) of sweet sorghum bioethanol production in Northeast China (NEC), Huang-Huai-Hai Basin (HHHB) and Ganxin Region (GX). 


\subsection{Sensitive Analysis of the Theoretical Net Economic Output under the Current Biomass Conversion Technology}

As an ideal solution to solve dual challenges of energy and environmental security, numerous new conversion technologies have been developed for bioethanol production over the past two decades [65]. However, few studies have been conducted to evaluate the cost of bioethanol conversion, which could be considered a crucial factor for the development of the bioethanol industry [66]. Furthermore, logistical challenges that have led to poor financial return have also been reported as main barriers to using sweet sorghum as bioethanol feedstock [1]. Thus, two sensitivity analyses were conducted to identify the effects of bioethanol conversion and biomass logistics costs on the prospective economic profitability in the three selected regions analyzed in this study. Based on the theoretical calculation (Equations (5)-(8)), the initial values of inputs for bioethanol conversion were 2884.7 USD/ha, 3085.3 USD/ha and 2552.8 USD/ha in NEC, HHHB and GX, respectively. Notably, a similar ranking order was seen for biomass logistics inputs as for bioethanol conversion, with the ranking of locations as NEC (3948.0 USD/ha) > HHHB (3734.4 USD/ha) > GX (3042.6 USD/ha). In order to evaluate economic viability, the initial values of bioethanol conversion inputs (Figure 7a) or biomass logistics inputs (Figure $7 \mathrm{~b}$ ) were decreased by increments of $10 \%$ in three selected regions. Meanwhile, the other parameters remained unchanged.

(a)

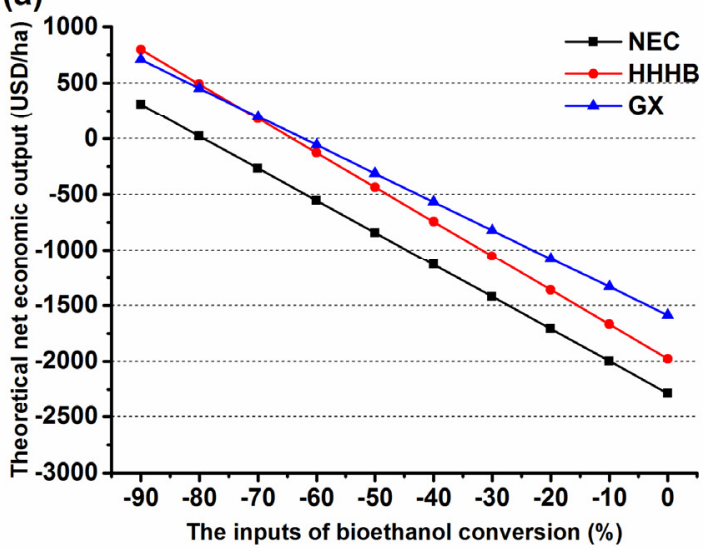

(b)

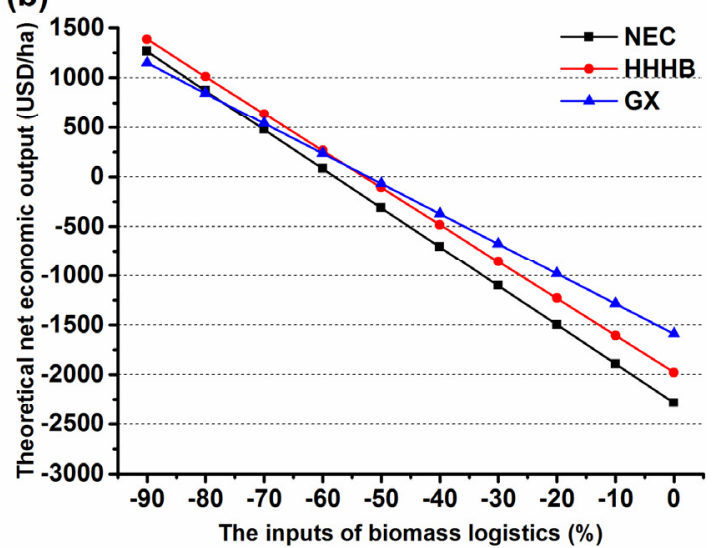

Figure 7. Sensitivity analysis of the theoretical net economic output of Advanced Solid-State Fermentation (ASSF) to assess the varying costs of bioethanol production (a) and biomass logistics (b).

Because of the cost structure presented earlier in Figure 6, it is obvious that proportionate biomass logistics cost reduction would lead to better prospective economic profitability than would proportionate reduction of bioethanol conversion cost. Ultimately, bioethanol production using sweet sorghum could achieve profitability in all of the selected areas when cost reduction of biomass logistics reached $60 \%$ (Figure $7 \mathrm{a}$ ). In this case, HHHB would achieve the highest average net economic output (264.6 USD/ha), followed by GX (234.0 USD/ha), with the lowest value for NEC (83.0 USD/ha). In addition, net economic output would be ranked in the order of HHHB (1012.1 USD/ha) > NEC (872.6 USD/ha) > GX (845.5 USD/ha) when cost reduction of bioethanol logistics reached $80 \%$. Nonetheless, these results still indicate that this process is far from economically feasible using the current biomass conversion processes in the selected regions, unless biomass conversion cost reductions reached $80 \%$ (Figure $7 \mathrm{~b}$ ). If such a large cost saving could be realized, the net economic outputs would be 490.38 USD/ha, 453.63 USD/ha and 21.94 USD/ha in HHHB, GX and NEC, respectively.

\section{Discussion}

Despite the fact that sweet sorghum is regarded as the most advantageous renewable bioenergy feedstock, its large-scale utilization for bioethanol production has not yet been realized in China [4]. 
Meanwhile, sustainability and economic feasibility studies of bioethanol production have mainly focused on a specific region or a single aspect of the bioethanol production process $[33,35,66-73]$. In addition, comprehensive assessment of sustainability and economic feasibility of sweet sorghum for bioethanol have been insufficient, even among various diverse areas across China.

In this study, the result from SPTM analysis first demonstrates that the NEC, GX and HHHB regions are the most suitable locations from a sorghum cultivation technological standpoint among all eight agricultural regions. Meanwhile, values for the degree of production maturity of the other five regions indicate they are all immature. This result is consistent with previous studies [3] that demonstrated that the NEC, HHHB and GX zones exhibited the highest potential for successful sweet sorghum cultivation for bioethanol production. Meanwhile, Li [27] suggested that the most promising of the unutilized land resources, after considering geographical condition for agricultural production, are Xinjiang and Inner-Mongolia, followed by the middle-lower Yangtze area and Loess Plateau and finally by Northeast China. In addition, Shi [74] reported that there were abundant forest resources and an advanced breeding research center in NEC, which was created to develop the bioenergy industry in coordination with use of forest residue and sweet sorghum as bioenergy feedstock. Therefore, these three areas, NEC, HHHB and GX, were recommended as the most feasible agricultural regions for large-scale sweet sorghum production.

As part of the sustainability analysis in this study, economic input and energy input of sweet sorghum production in GX were higher than those in NEC and HHHB; both higher inputs were primarily due to expensive labor costs and high labor intensity requirements during the field planting stage [33,35]. A previous study [75] had reported that economic efficiency of sweet sorghum planted on marginal land in Italy was superior to economic efficiency on fertile land, due to a lack of subsidies provided for sweet sorghum planting on the fertile land. In this study, great differences in economic output were observed between Wuyuan County and Gulang County in GX, mostly because the sweet sorghum variety in Gulang County is late-maturing and no-heading and has a higher stalk biomass; thus, stalk from Gulang County commands a higher price (57 USD/t) than from Wuyuan County (33 USD/t). Previous sweet sorghum life cycle assessment studies revealed that the GHGs were produced at their highest levels during the planting stage, as a result of $\mathrm{N}$-fertilizer production and application, as well as the use of diesel fuel for farm machinery during this stage [22,71]. Other research [76] reported that in the North China Plain, using diversified crop rotation planting, the production of $\mathrm{N}$ fertilizer made the largest contribution to GHG emissions among all agricultural inputs, accounting for an average of $45 \%$ of emissions. The impact of $\mathrm{N}$ fertilizer application on total emissions, including direct $\mathrm{N}_{2} \mathrm{O}$ emissions from $\mathrm{N}$ fertilizer application and indirect $\mathrm{N}_{2} \mathrm{O}$ emissions from volatilized $\mathrm{NH}_{3}-\mathrm{N}$ and $\mathrm{NO}_{x}-\mathrm{N}$ and from nitrate leaching, accounted for an average $37 \%$ of total emissions. Another study [77] reported that the sizeable $\mathrm{N}$ fertilizer application amount and intensity in HHHB (especially in Shandong as a typical agricultural province) resulted in the markedly lower $\mathrm{N}$ fertilizer use efficiency than observed for NEC. No obvious differences were observed in soil and staple crop yields in two principal planting regions, HHHB and NEC. In this work, sustainability of sweet sorghum planting was highest in NEC but relatively lower in GX. In northwest China, including Xinjiang Province and the area north of the Great Wall, sweet sorghum has already been planted extensively. However, in these regions, the short frost-free period seriously restricts large-scale cultivation of sweet sorghum for bioenergy production. In the northwest area, the economic characteristics of bioenergy sweet sorghum are not stable and the temperature descends rapidly after harvest, which is favorable for storage but not for the crushing and fermentation of stalks requiring extra energy and economic inputs [78]. Besides concerns of energy efficiency, economic benefit and GHG emissions from sweet sorghum production, erratic weather, agricultural development and the resource potential of marginal land must also be considered before choosing a location for actual production.

This study evaluated an advanced conversion process based on current biomass feedstock supplies, beyond the state of bioethanol conversion technology in China, to evaluate the theoretical 
productive potential and prospective economic profitability of sweet sorghum bioethanol in the three selected sites. Previous studies reported difficulties in comparing energy and water consumption for previously common liquid-state ethanol production methods [79]. Since then, due to its higher energy efficiency and lower water utilization [80], solid-state fermentation is now considered preferable to liquid-state fermentation. However, the absence of free water during solid-state fermentation leads to poor heating efficiency [61]. In the present study, the process that was considered was based on Advanced Solid-State Fermentation (ASSF) technology, which could overcome the aforementioned disadvantages $[69,70]$. As a result, the theoretical bioethanol potential was around 5228.7-6322.4 L/ha for the three selected agricultural regions if the ASSF technology were used there, which was higher than values obtained in previous studies $[14,15,21,81]$. Nevertheless, Figure 6 indicates that bioethanol production using sweet sorghum is still not economically feasible using processes currently used in the selected regions, due to high cost input of the bioethanol conversion and biomass logistics and the price commanded by the ethanol product.

As discussed in this paper, bioethanol production using sweet sorghum fell far short of achieving profitability using current technologies in China. One study [1] reported that sweet sorghum stalks were used inefficiently in China because they are grown in geographically dispersed areas with low energy density under the current system. Moreover, the main barrier to using biomass as a source of biofuel has been a logistics challenge rather than a technological one [1]. Consistent with the results of this study, the costs of biomass logistics were rather higher than bioethanol conversion inputs in all selected regions (Figure 6) mostly due to the lack of mechanization. One study indicated that the price of sweet sorghum logistics could decrease to $35.76 \mathrm{USD} / \mathrm{t}$ when the related system was well mechanized [1]. Hence, for bioenergy to succeed it appears most critical to increase the mechanization of the biomass logistics system. In tandem, new bioethanol production technologies should be developed to reduce total input costs of bioethanol production. It has been demonstrated [66] that a sustainable strategy of bioethanol production in China cannot be based only on sweet sorghum starch and juice; lignocellulosic bioethanol derived from sorghum bagasse could bring in more revenue per unit of feedstock than the current biomass mix. In addition, a recent study using a novel combined sweet sorghum bioethanol and power (CEP) model displayed a superior profitability than the currently used process [82]. From an economic sustainability standpoint, development of new technologies to convert all carbohydrates (including grain, juice and lignocellulose) in sweet sorghum into bioethanol and byproduct is urgently needed. Beyond this, genetic modification of energy crops has shown the promise to significantly enhance biomass yield and biofuel production, which could reduce the input of sweet sorghum logistics and bioethanol production [83]. So, genetic modification of sweet sorghum as a bioenergy crop also needs to be put on the agenda.

\section{Conclusions}

Sweet sorghum is becoming one of the most promising bioenergy crops in China. In this study, the technical feasibility of sweet sorghum production was assessed in eight agricultural regions in China using our high-throughput SPTM model. Next, comprehensive assessment of sustainability of sweet sorghum production (including net economic output, economic input-output ratio, net energy output, energy input-output ratio, greenhouse gas emissions and nitrogen use efficiency) was conducted for three selected typical agricultural regions, NEC, HHHB and GX. Results showed that the degree of technical maturity (DTM) of bioethanol production was relatively high in NEC (0.8066), followed by the value of GX (0.7531) and next by HHHB (0.6594); the DTM values of the other five regions were very immature and possessed degrees less than 0.5 . From an economic point of view, bioethanol production from sweet sorghum is not feasible at China's current agricultural logistics and biofuel conversion stages of development. Thus, more efforts are needed to improve biomass logistics such as the dedicated equipment for mechanization, transport distance from depot, diesel price, transport distance from field side and baler rate to decrease total costs. Meanwhile, the development of new bioethanol production technologies also needs to be sped up. 
Supplementary Materials: The following are available online at http:/ / www.mdpi.com/2071-1050/10/3/731/s1, Table S1: Indicators of the sustainability of sweet sorghum production of typical study sites in Northeast China, Huang-Huai-Hai Basin, and Ganxin Region.

Acknowledgments: This work was supported by the National Natural Science Foundation (31470555).

Author Contributions: X.Y. wrote the paper; X.Y. and G.X. conceived and designed this research; X.Y., H.L. and M.L. analyzed the data; L.R. contributed to materials.

Conflicts of Interest: The authors declare no conflict of interest.

\section{References}

1. Ren, L.T.; Cafferty, K.; Roni, M.; Jacobson, J.; Xie, G.H.; Ovard, L.; Wright, C. Analyzing and comparing biomass feedstock supply systems in China: Corn stover and sweet sorghum case studies. Energies 2015, 8, 5577-5597. [CrossRef]

2. IEA. Sustainable Production of Second-Generation Biofuels: Potential and Perspectives in Major Economies and Developing Countries; IEA: Paris, France, 2010.

3. Zhang, C.; Xie, G.; Li, S.; Ge, L.; He, T. The productive potentials of sweet sorghum ethanol in China. Appl. Energy 2010, 87, 2360-2368. [CrossRef]

4. Farrell, A.E.; Plevin, R.J.; Turner, B.T.; Jones, A.D.; O'Hare, M.; Kammen, D.M. Ethanol can contribute to energy and environmental goals. Science 2006, 311, 506-508. [CrossRef] [PubMed]

5. Lehmann, J. A handful of carbon. Nature 2207, 447, 143. [CrossRef] [PubMed]

6. Qiu, H.; Huang, J.; Keyzer, M.; Van, V.W.; Rozelle, S.; Fisher, G.; Ermolieva, T. Biofuel development, food security and the use of marginal land in China. J. Environ. Qual. 2011, 40, 1058. [CrossRef] [PubMed]

7. Fargione, J.E.; Cooper, T.R.; Flaspohler, D.J.; Hill, J.; Lehman, C.; Tilman, D.; Mccoy, T.; Mcleod, S.; Nelson, E.J.; Oberhauser, K.S. Bioenergy and Wildlife: Threats and Opportunities for Grassland Conservation. BioScience 2009, 59, 767-777. [CrossRef]

8. Bonin, C.; Lal, R. Agronomic and ecological implications of biofuels. Adv. Agron. 2012, 117, 1-50.

9. Yang, Z.; Zhao, L.; Liu, J. The present situation of soil fertility, organic and inorganic fertilizer application and suggestion of fertilizer application. Heilongjiang Agric. Sci. 2005, 4, 39.

10. Han, K.J.; Pitman, W.D.; Misook, K.; Day, D.F.; Alison, M.W.; Mccormick, M.E.; Aita, G. Ethanol production potential of sweet sorghum assessed using forage fiber analysis procedures. GCB Bioenergy 2013, 5, 358-366. [CrossRef]

11. Vasilakoglou, I.; Dhima, K.; Karagiannidis, N.; Gatsis, T. Sweet sorghum productivity for biofuels under increased soil salinity and reduced irrigation. Field Crop. Res. 2011, 120, 38-46. [CrossRef]

12. Zhang, F.Y.; Zhao, W.J.; Ping, J.A. Macroergic Crop-Sweet Sorghum. Rev. China Agric. Sci. Technol. 2006, 1, $14-17$.

13. Tang, S.; Xi, Z. The prospect of sweet sorghum in bioenergy industry. Curr. Biotechnol. 2012, 2, 81-86.

14. Zhao, Y.L.; Dolat, A.; Steinberger, Y.; Wang, X.; Osman, A.; Xie, G.H. Biomass yield and changes in chemical composition of sweet sorghum cultivars grown for biofuel. Field Crop. Res. 2009, 111, 55-64. [CrossRef]

15. Zhao, Y.L.; Steinberger, Y.; Shi, M.; Han, L.P.; Xie, G.H. Changes in stem composition and harvested produce of sweet sorghum during the period from maturity to a sequence of delayed harvest dates. Biomass Bioenergy 2012, 39, 261-273. [CrossRef]

16. Ratnavathi, C.V.; Suresh, K.; Kumar, B.S.V.; Pallavi, M.; Komala, V.V.; Seetharama, N. Study on genotypic variation for ethanol production from sweet sorghum juice. Biomass Bioenergy 2010, 34, 947-952. [CrossRef]

17. Jiang, S.Y.; Ma, Z.; Vanitha, J.; Ramachandran, S. Genetic variation and expression diversity between grain and sweet sorghum lines. BMC Genom. 2013, 14, 18. [CrossRef] [PubMed]

18. Han, L.P.; Guo, X.Q.; Yu, Y.J.; Duan, L.S.; Rao, M.S.; Xie, G.H. Effect of prohexadione-calcium, maleic hydrazide and glyphosine on lodging rate and sugar content of sweet sorghum. Res. Crops 2011, 12, 230-238. [CrossRef]

19. Xue, S.; Han, D.Q.; Yu, Y.J.; Steinberger, Y.; Han, L.P.; Xie, G.H. Dynamics in elongation and dry weight of internodes in sweet sorghum plants. Field Crop. Res. 2012, 126, 37-44. [CrossRef]

20. Han, K.J.; Pitman, W.D.; Alison, M.W.; Harrell, D.L.; Viator, H.P.; Mccormick, M.E.; Gravois, K.A.; Kim, M.; Day, D.F. Agronomic Considerations for Sweet Sorghum Biofuel Production in the South-Central USA. Bioenergy Res. 2012, 5, 748-758. [CrossRef] 
21. Zegada-Lizarazu, W.; Monti, A. Are we ready to cultivate sweet sorghum as a bioenergy feedstock? A review on field management practices. Biomass Bioenergy 2012, 40, 1-12. [CrossRef]

22. Erickson, J.E.; Woodard, K.R.; Sollenberger, L.E. Optimizing sweet sorghum production for biofuel in the southeastern USA through nitrogen fertilization and top removal. Bioenergy Res. 2012, 5, 86-94. [CrossRef]

23. Holou, R.A.Y.; Stevens, G. Juice, sugar, and bagasse response of sweet sorghum (Sorghum bicolor (L.) Moench Cv. M81E) to N fertilization and soil type. GCB Bioenergy 2012, 4, 302-310. [CrossRef]

24. Han, L.P.; Steinberger, Y.; Zhao, Y.L.; Xie, G.H. Accumulation and partitioning of nitrogen, phosphorus and potassium in different varieties of sweet sorghum. Field Crop. Res. 2011, 120, 230-240. [CrossRef]

25. Tew, T.L.; Cobill, R.M.; Richard, E.P.J. Evaluation of sweet sorghum and sorghum $\times$ sudangrass hybrids as feedstocks for ethanol production. Bioenergy Res. 2008, 1, 147-152. [CrossRef]

26. Wang, J.S.; Wang, M.L.; Spiertz, J.H.J.; Liu, Z.X.; Han, L.P.; Xie, G.H. Genetic variation in yield and chemical composition of wide range of sorghum accessions grown in north-west China. Res. Crops 2013, 14, 95-105.

27. Li, C. Improved varieties sweet sorghum for feedstock, sugar and energy production. Bull. Agric. Sci. Technol. 2003, 2, 23.

28. Tang, C.; Luo, F.; Li, X.; Pei, Z.; Gao, J.; Sun, S. Responsiveness of Sweet Sorghum in Yield and Quality Related Traits to Environmental Factors. Acta Agron. Sin. 2015, 41, 1612-1618. [CrossRef]

29. Li, D. Ethanol Fuel from Sweet Sorghum Desiderates development. J. Agric. Sci. Technol.-Iran 2003, 4, 48-51.

30. Zhao, L.; Ou, X.; Chang, S. Life-cycle greenhouse gas emission and energy use of bioethanol produced from corn stover in China: Current perspectives and future prospectives. Energy 2016, 115, 303-313. [CrossRef]

31. Wang, J.C.; Dai, L.; Tian, Y.S.; Qin, S.P. Analysis of the development status and trends of biomass energy industry in China. Trans. Chin. Soc. Agric. Eng. 2007, 23, 276-282.

32. De Vries, S.C.; Van de Ven, G.W.J.; Van Ittersum, M.K.; Giller, K.E. Resource use efficiency and environmental performance of nine major biofuel crops, processed by first-generation conversion techniques. Biomass Bioenergy 2010, 34, 588-601. [CrossRef]

33. Ren, L.T.; Liu, Z.X.; Wei, T.Y.; Xie, G.H. Evaluation of energy input and output of sweet sorghum grown as a bioenergy crop on coastal saline-alkali land. Energy 2012, 47, 166-173. [CrossRef]

34. Giller, K.E. The production-ecological sustainability of cassava, sugarcane and sweet sorghum cultivation for bioethanol in Mozambique. GCB Bioenergy 2011, 4, 20-35.

35. Liu, H.H.; Ren, L.T.; Spiertz, H.; Zhu, Y.B.; Xie, G.H. An economic analysis of sweet sorghum cultivation for ethanol production in North China. GCB Bioenergy 2015, 7, 1176-1184. [CrossRef]

36. Weng, X.W.; Liu, G.Q.; Liu, D.Q.; Chen, Y.S.; Feng, R.; Li, M.; Dong, R.J. Survey and analysis on economic benefit of sorgo to fuel ethanol production-with sorgo to fuel ethanol project in Huachuan county, Heilongjiang Province as example. Renew. Energy Resour. 2008, 26, 86-89. (In Chinese)

37. Zhang, C.; Xie, G.; Li, S.; Ge, L.; Qi, Y. Spatial suitability and its bio-ethanol potential of sweet sorghum in China. Acta Ecol. Sin. 2010, 30, 4765-4770.

38. Linton, J.A.; Miller, J.C.; Little, R.D.; Petrolia, D.R.; Coble, K.H. Economic feasibility of producing sweet sorghum as an ethanol feedstock in the southeastern United States. Biomass Bioenergy 2011, 35, 3050-3057. [CrossRef]

39. Committee of National Agricultural Regionalization. Agricultural Resources and Regional Planning in China; China Agriculture Press: Beijing, China, 1991.

40. Lu, Q.; Zhou, J.; Zhang, F.; Guo, Z.; Lang, L. Sweet Sorghum; China Agriculture Science Press: Beijing, China, 2008.

41. Deng, J. Control problems of grey systems. Syst. Control Lett. 1982, 1, 288-294.

42. Shi, L.; Sun, H. Drought control analysis on Yuelai irrigation area in Huachuan County. J. Heilongjiang Hydraul. Eng. Coll. 2002, 29, 136-137.

43. Zhang, Y.; Wang, D.; Zhao, Y.; Wang, J.; Chen, S. The main diseases and insect pests occurrence and prevention countermeasures in Morin Dawa artificial grassland of Inner Mongolia. Prat. Sci. 2004, 21, 52-54.

44. Li, F. The introduction of soil erosion present situation and the countermeasures in Morin Dawa. Inn. Mong. Water Resour. 2007, 4, 99-100.

45. Wang, J.; Su, L. The analysis and evaluation of new reservoir land reclamation project in Dawoer community of Morin Dawa autonomous county, Hulunbeier City. Westem Resour. 2014, 1, 113-115.

46. Wang, J. Study on the Suitable Applying Amount of Nitrogen and Phosphorus Fertilizer on the Tide Soil Cotton Field at Binzhou. Master's Thesis, Shandong Agricultural University, Tai'an, China, 2005. 
47. Wang, K. The productive cultivation techniques of Wudi gold silk jujube. North. Fruits. 1999, 3, 17-18. (In Chinese)

48. Shi, L. Study on Determination of Canal Water Use Efficiency in Bojili Irrigation District, Binzhou City, Shandong Province. Master's Thesis, China Agricultural University, Beijing, China, 2007.

49. Zheng, F.; Luo, W.; Li, L.; Feng, Y. Soil nutrient and microorganism of Pinus thunbergli forest in Weihai. Ecol. Environ. Sci. 2008, 17, 1590-1594.

50. Zhao, J. The health assessment of the agro-ecosystem in Weihai city of Shandong province. Master's Thesis, Shandong Agricultural University, Tai'an, China, 2004.

51. Ding, J.; Li, H.; Li, C.; Zhang, Z.; Zhang, E. Effects of different fertilization treatments on soil moisture from 0 to $100 \mathrm{~cm}$ in the late growth stage of Maize. Mod. Agric. Sci. Technol. 2008, 15, 205-206.

52. Zhu, J. Development of Eco-milk and Local Milk Products in TURPAN. Master's Thesis, Gansu Agricultural University, Lanzhou, China, 2005.

53. Guo, H.; Liang, J.; Guo, F. The application of balanced fertilization technology of seedless grape. Xinjiang Agric. Sci. Technol. 2009, 4, 67.

54. Hao, J. Research on country territory agricultural land grade appraise in Hetao region-take the Wuyuan country of Inner Mongolia as the example. Master's Thesis, Inner Mongolia Normal University, Huhehaote, China, 2009.

55. Lei, $\mathrm{Q}$. The study on sunflower production present situation and development countermeasure in Wuyuan county of Bayannur in Inner Mongolian. Master's Thesis, Inner Mongolia Agricultural University, Huhehaote, China, 2008.

56. Xue, Z.; Shi, H.; Guo, Y.; Zhang, Y.; Yan, H.; Li, L. Effects of coupling of soil water and fertilizer on the growth of sunflower during its seeding period in saline soil. Trans. Chin. Soc. Agric. Eng. 2007, 3, 91-94.

57. Wang, F.; Wang, J.; Huang, S. Report of Introduction Demonstration Experiment of Sweet Sorghum. Sugar Crops China 2013, 3, 47-48.

58. Wang, T. The research on the development of the grassland vegetation during the course of the improvement and recovery of the grassland in the northern deserts of Gulang County. Pratacult. Sci. 2005, 8, 14-16.

59. Zhang, J. Effects of different land use patterns on soil structure and properties in yellow Irrigation District of Gulang County. Mod. Agric. Sci. Technol. 2009, 21, 222-223.

60. Baligar, V.; Fageria, N.; He, Z. Nutrient use efficiency in plants. Commun. Soil Sci. Plant Anal. 2001, 32, 921-950. [CrossRef]

61. Li, S.; Li, G.; Zhang, L.; Zhou, Z.; Han, B.; Hou, W.; Wang, J.; Li, T. A demonstration study of ethanol production from sweet sorghum stems with advanced solid state fermentation technology. Appl. Energy 2013, 102, 260-265. [CrossRef]

62. Tan, X.P. Exploration in superiorities and economic characters of several crops for automobile use alcohol producing. Renew. Energy Resour. 2007, 25, 21-30.

63. Gao, H.; Hu, S.Y.; Li, Y.R.; Chen, D.J.; Bing, Z. Greenhouse gas emission of sweet sorghum ethanol in life-cycle. Trans. Chin. Soc. Agric. Eng. 2012, 28, 178-183.

64. Wei, Y.Q.; Ren, X.; Bei, Z.L. Commercialization analysis of sweet sorghum based bioethanol on salt farm land in China. J. Anhui Agric. Sci. 2010, 38, 11279-11282.

65. Rooney, W.L.; Blumenthal, J.; Bean, B.; Mullet, J.E. Designing sorghum as a dedicated bioenergy feedstock. Biofuels Bioprod. Biorefin. 2007, 1, 147-157. [CrossRef]

66. Gnansounou, E.; Dauriat, A.; Wyman, C.E. Refining sweet sorghum to ethanol and sugar: Economic tradeoffs in the context of North China. Bioresour. Technol. 2005, 96, 985-1002. [CrossRef] [PubMed]

67. Chen, F.; Ameen, A.; Tang, C.C.; Du, F.; Yang, X.L.; Xie, G.H. Effects of Nitrogen Fertilization on Soil Nitrogen for Energy Sorghum on Marginal Land in China. Agron. J. 2017, 109, 636. [CrossRef]

68. Yang, L.; Wang, X.Y.; Han, L.P.; Spiertz, H.; Liao, S.H.; Wei, M.G.; Xie, G.H. A quantitative assessment of crop residue feedstocks for biofuel in North and Northeast China. GCB Bioenergy 2015, 7, 100-111. [CrossRef]

69. Wang, M.; Chen, Y.; Xia, X.; Li, J.; Liu, J. Energy efficiency and environmental performance of bioethanol production from sweet sorghum stem based on life cycle analysis. Bioresour. Technol. 2014, 163, 74-81. [CrossRef] [PubMed]

70. Wang, M.; Pan, X.; Xia, X.; Xi, B.; Wang, L. Environmental sustainability of bioethanol produced from sweet sorghum stem on saline-alkali land. Bioresour. Technol. 2015, 187, 113-119. [CrossRef] [PubMed]

71. Zhang, T.; Xie, X.; Huang, Z. Life Cycle Water footprints of nonfood biomass fuels in China. Environ. Sci. Technol. 2014, 48, 4137-4144. [CrossRef] [PubMed] 
72. Fu, H.; Meng, F.; Molatudi, R.L.; Zhang, B. Sorghum and switchgrass as biofuel feedstocks on marginal lands in Northern China. Bioenergy Res. 2016, 9, 633-642. [CrossRef]

73. Liang, S.; Xu, M.; Zhang, T. Unintended consequences of bioethanol feedstock choice in China. Bioresour. Technol. 2012, 125, 312-317. [CrossRef] [PubMed]

74. Shi, Y.C. Jue Sheng Sheng Wu Zhi; China Agricultural University Press: Beijing, China, 2011.

75. Caserta, G.; Bartolelli, V.; Mutinati, G. Herbaceous energy crops: A general survey and a microeconomic analysis. Biomass Bioenergy 1995, 9, 45-52. [CrossRef]

76. Yang, X.L.; Gao, W.S.; Zhang, M.; Chen, Y.Q.; Sui, P. Reducing agricultural carbon footprint through diversified crop rotation systems in the North China Plain. J. Clean. Prod. 2014, 76, 131-139. [CrossRef]

77. Zhao, X.; Hu, K.; Li, K.; Wang, P.; Ma, Y.; Stahr, K. Effect of optimal irrigation, different fertilization, and reduced tillage on soil organic carbon storage and crop yields in the North China Plain. J. Plant Nutr. Soil Sci. 2013, 176, 89-98. [CrossRef]

78. Du, R.; Li, S.; Liu, G.; Ji, G.; Hou, S.; Ma, X.; Wang, J.; Yang, N. Analysis on key factors of sweet sorghum as raw material for bio-fuel production. J. China Agric. Univ. 2012, 17, 70-75.

79. Wu, X.; Scott, S.; Johathanl, P.; Williaml, R.; Yu, J.; Wang, D. Features of sweet sorghum juice and their performance in ethanol fermentation. Ind. Crops Prod. 2010, 31, 164-170. [CrossRef]

80. Kwon, Y.J.; Wang, F.; Liu, C.Z. Deep-bed solid state fermentation of sweet sorghum stalk to ethanol by thermotolerant Issatchenkia orientalis IPE 100. Bioresour. Technol. 2011, 102, 11262. [CrossRef] [PubMed]

81. Regassa, T.H.; Wortmann, C.S. Sweet sorghum as a bioenergy crop: Literature review. Biomass Bioenergy 2014, 64, 348-355. [CrossRef]

82. Zhang, L.; Zu, X.; Fu, J.; Li, J.; Li, S. A Novel Combined Ethanol and Power Model of Microgrid Driven by Sweet Sorghum Stalks Using ASSF. Energy Procedia 2016, 103, 244-249. [CrossRef]

83. Wang, Y.; Fan, C.; Hu, H.; Li, Y.; Sun, D.; Wang, Y.; Peng, L. Genetic modification of plant cell walls to enhance biomass yield and biofuel production in bioenergy crops. Biotechnol. Adv. 2016, 34, 997-1017. [CrossRef] [PubMed] 